How Predictable are Environmental Compliance Inspections?

\author{
Sarah Stafford \\ College of William and Mary
}

College of William and Mary

Department of Economics

Working Paper Number 143

Current Version: August 2013 
COLLEGE OF WILLIAM AND MARY

DEPARTMENT OF ECONOMICS

WORKING PAPER \# 143

August 2013

\section{How Predictable are Environmental Compliance Inspections?}

The goal of this paper is to examine the timing of environmental compliance inspections and determine the extent to which such inspections can be predicted. The paper focuses on modeling the inspections at hazardous waste facilities in the U.S. using detailed data on individual inspections and facilities. The paper uses a number of parametric and semi-parametric duration models to predict the timing of inspections and finds that the Exponential model provides the best balance in terms of the explanatory power and simplicity of the model. However, even with this model it is difficult to accurately predict the timing of most compliance inspections. The paper also examines the extent to which using data on individual inspections can improve empirical predictions about aggregate inspections. If the goal is to estimate the annual number of inspections at hazardous waste facilities, neither the Exponential model or a Poisson model is clearly superior. Which model is more appropriate depends on the question the researcher wants to answer. Similarly, if the focus is on whether any inspection occurred in a given time period, the benefits of using the Exponential model depend on the nature of the questions to be answered. While the Exponential model performs better than a Probit model in predicting which entities will be inspected, it also results in a higher number of "false positives," that is predicting an inspection when no inspection actually occurs.

Key Words: Hazardous Waste, Duration Model, Inspection Timing

Sarah Stafford

Department of Economics

College of William and Mary

Williamsburg, VA 23187-8795

slstaf@wm.edu 


\section{How Predictable are Environmental Compliance Inspections?}

\section{Introduction}

In the U.S. many major environmental regulations are enforced using a deterrenceframework: that is, regulations are enforced through unannounced compliance inspections and fines for any violations discovered during the course of those inspections. According to Gray and Shimshack (2011), most policy-makers and scholars generally believe that effective pollution regulations require an enforcement regime that includes recurrent inspections and sanctions, and survey evidence suggests that a traditional regulatory structure with rigorous monitoring and enforcement is a primary motivator of facilities' environmental compliance decisions.

Numerous empirical studies covering a wide range of environmental regulations and regulated populations provide evidence that deterrence-based enforcement does increase compliance rates. For example, Gray and Deily (1996) and Gray and Shadbegian (2005) examine air pollution compliance for steel mills and pulp and paper mills in the U.S., respectively, and find that both inspections and enforcement actions have a statistically significant positive impact on compliance. Looking at compliance with U.S. water regulations, Earnhart (2004) and Glicksman and Earnhart (2007) similarly find that inspections and sanctions deter violations at water treatment plants and chemical facilities, respectively. Stafford (2002) shows that compliance inspections and penalties for violations have a significant deterrent effect on violations at facilities subject to hazardous waste regulations. ${ }^{1}$

Most theoretical models of deterrence-based enforcement assume that compliance inspections are probabilistic - that is, a regulated entity knows the likelihood that compliance inspection may occur, but not whether one is or is not going to occur with certainty during any particular period. If compliance inspections are completely predictable, regulated entities would only comply when an inspection was going to occur. By making inspections probabilistic, regulators can deter more violations using fewer resources because as long as the expected cost of violation - that is, the probability of an

${ }^{1}$ See Gray and Shimshack (2011) for a comprehensive survey of the empirical literature on environmental monitoring and enforcement. 
inspection times the sanction for a violation - exceeds the cost of compliance, facilities will comply.

In practice, however, it is not clear whether compliance inspections really are unpredictable. For example, it is reasonable to think that the probability that a facility is inspected may depend on how long it has been since the last inspection, particularly if a regulatory agency's charge is to inspect each facility at least once every two years. ${ }^{2}$ If the timing of a compliance inspection depends on the length of time since the last inspection, facilities may be able to roughly predict when a compliance inspection will occur and adjust their compliance decisions accordingly, decreasing the deterrent effect of the inspection. The primary objective of this paper is to examine the timing of environmental compliance inspections and determine the extent to which such inspections can be predicted. More specifically, this paper focuses on modeling the timing of compliance inspections conducted at hazardous waste generators using data on individual inspections over an eleven-year time period. If compliance inspections have become predictable, policymakers looking to increase environmental compliance may find it effective to redesign their monitoring strategy.

A secondary objective of this paper is to determine the extent to which using detailed information on individual inspections can improve empirical predictions of the timing of inspections. Many empirical analyses of enforcement and compliance need to estimate the likelihood of an inspection or the number of inspections for a given time period. For the most part, such studies estimate inspections for a particular time period based on aggregated data (e.g., monthly or annual inspections). However, it may be the case that using detailed information on individual inspections can improve empirical predictions of the likelihood and number of inspections.

The remainder of the paper is organized as follows: Section 2 provides a theoretical framework for the empirical analysis and discusses the related literature. Section 3 discusses the institutional setting for the analysis, namely the inspection regime for EPA's

2 For example, Section 3007 of the Resource Conservation and Recovery Act requires that EPA or an authorized state conduct a program to "thoroughly inspect" every hazardous waste treatment, storage, or disposal facility "no less often than every two years" (42 U.S.C. $\S$ 6927). 
hazardous waste program. Section 4 presents the econometric methodology while Section 5 describes the data used in the analysis. Section 6 presents the results of the duration models and Section 7 compares the duration results to other more common models of inspections. Finally, Section 8 concludes.

\section{Theoretical Framework and Related Literature}

The deterrence approach to environmental regulation is based on Becker's (1968) seminal paper on the economics of crime, which assumes that individuals are rational, and will commit a crime whenever the expected benefit of the crime to the individual is greater than the expected cost of the crime to the individual. To deter crimes, the government can increase the expected cost of crime either by increasing the likelihood that a crime is detected or the punishment associated with a crime. Becker's initial model has spawned a large literature on the economics of crime as well as a literature on regulatory enforcement that starts with the same basic assumption that violators make decisions based on a rational comparison of costs. ${ }^{3}$

Russell, Harrington, and Vaughn (1986) were one of the first to take the general models on the economics of crime and explicitly apply them to environmental regulation. In the context of environmental regulations, if policy makers want to deter environmental violations they can either increase the likelihood that a violation is detected or increase the sanctions associated with detected violations. Over the last several decades many additional models of environmental compliance and enforcement have been built on this "rational polluter" framework, extending the basic model by allowing for complexities such as imperfect information, self-reporting, and principal-agent relationships, to name a few. While the majority of these extensions assume a static setting, there are several papers that have presented dynamic models on enforcement and compliance. ${ }^{4}$ One of the most influential of these models is Harrington's (1988) targeted enforcement model which uses changes in future inspection activity to motivate current compliance and shows that such a regime can maintain a higher level of compliance than can be obtained through more traditional, non-targeted enforcement. Harrington's model has been extended theoretically

${ }^{3}$ See Polinsky and Shavell (2000) for an overview of this literature.

${ }^{4}$ See Cohen (1999) and Heyes (2000) for surveys of this literature. 
by a number of papers (see, for example, Harford and Harrington (1991), Raymond (1999), Friesen (2003)) and has also been the focus of a number of empirical studies (see for example, Helland (1998), Nyborg and Telle (2006), and Stafford (2007)).

While both the theoretical targeting models and the empirical tests of such models have explicitly examined the relationship between past and future compliance and enforcement, the models and estimates have used a series of discrete time periods such as months or years rather than looking at inspections continuously across time. For example, most empirical studies of enforcement estimate the likelihood of an inspection for a given time period (or in some cases the number of inspections for a given time period) choosing the time period for the analysis based on the type of data available. There is only one study other than this one that focuses explicitly on inspection timing, Rousseau (2007). In that paper, Rousseau examines the regulatory inspection history of textile plants in Flanders using a duration model. ${ }^{5}$ More specifically, she uses a Cox partial likelihood model to estimate the length of time between environmental inspections for textile plants based on the plants' characteristics and past compliance statuses. She finds that the Flemish environmental inspection agency does use targeting, particularly targeting based on past compliance behavior and the plants' overall capacity, to select the plants that it inspects. However, since the focus of her paper is to examine the extent of targeting, Rousseau does not analyze whether a duration model provides a better fit to the data than a standard model.

This paper differs from that of Rousseau in two primary ways. First, and most obvious, this paper looks at U.S. hazardous waste inspections across a wide range of industries as opposed to Flemish environmental inspections at textile plants across a variety of media (e.g., water pollution, air pollution, toxic substances). Second, this paper uses multiple different duration analyses in order to assess how well different duration models predict inspections. Moreover, it compares the predictions of the duration models to the predictions of more commonly used empirical models to determine whether using additional data on individual inspections provides a more accurate estimate of inspection probability than what can be achieved using aggregate data.

${ }^{5}$ Nadeau (1997) estimates a duration model of plant non-compliance in the U.S., but chooses to model inspections as a Poisson process. 


\section{Institutional Setting}

Because environmental regulation in the U.S. is the result of a series of different pieces of legislation, there are separate media programs that regulate air pollution, water pollution, and hazardous waste. Each program tracks the individual facilities that it regulates separately and has its own enforcement regime. An inspection conducted by the air program focuses on determining compliance with air regulations, not water or hazardous waste regulations. ${ }^{6}$ Thus, in examining the timing of environmental inspections it makes sense to focus on one particular media program. This paper focuses on the hazardous waste program because regulatory inspections are the primary method for enforcing hazardous waste regulations, as hazardous waste facilities are not required to self-report compliance status. ${ }^{7}$

Hazardous waste is regulated under the Resource Conservation and Recovery Act (RCRA). RCRA Subtitle C, Section $§ 3007$ gives EPA the authority to conduct compliance and evaluation inspections of hazardous waste facilities for the purpose of developing regulations, preparing permits, or ensuring compliance with RCRA regulations. Regulated entities must grant authorized officials access to all records at hazardous waste management facilities at all reasonable times and must allow officials to obtain samples of any wastes present and determine compliance with all applicable requirements of RCRA. ${ }^{8}$

There are a number of different types of inspections. Some inspections are not focused on enforcement but instead are designed to collect information to help EPA develop new rulemakings or are compliance assistance inspections conducted at the request of the regulated entity. While these types of inspections will be scheduled in

\footnotetext{
${ }^{6}$ Programs can co-operate and conduct multi-media inspections, but the majority of inspections are single program inspections.

${ }^{7}$ Both the Clean Air Act and Clean Water Act require regulated entities to self-report compliance status.

8 Under the U.S. Supreme Court decision in Marshall v. Barlow (436 U.S. 307, 322-24 (1978)), business owners and operators have an expectation of privacy against unreasonable administrative searches of their commercial property and warrantless searches cannot generally be conducted. However, there is an exception for "pervasively regulated businesses" subject to "longstanding governmental regulation." Additionally, probable cause for obtaining a warrant can be established by showing that the entity is being inspected according to a neutral inspection regime. In practice, few entities challenge EPA inspections without warrants (Steinway, 2009).
} 
conjunction with the facility, EPA's policy is that compliance inspections are unannounced. The primary types of compliance inspections include:

- $\quad$ Compliance Evaluation Inspections - Routine inspections to evaluate compliance with RCRA. These inspections usually encompass a file review prior to the site visit; an on-site examination of generation, treatment, storage, or disposal areas; a review of records; and an evaluation of the facility's compliance with RCRA.

- $\quad$ Focused Compliance Inspections - Inspections that address only a specific portion of the RCRA regulations.

- $\quad$ Ground Water Monitoring Evaluations - Inspections to ensure that ground water monitoring systems are designed and functioning properly at RCRA land disposal facilities.

- $\quad$ Compliance Schedule Evaluations - Inspections that verify compliance with an compliance schedule following a formal enforcement action.

- $\quad$ Operations and Maintenance Inspections - Inspections to ensure that ground water monitoring and other systems at closed land disposal facilities continue to function properly.

- $\quad$ Corrective Action Compliance Evaluations - Evaluations of a site's compliance with the corrective action requirements of a permit or an order.

- $\quad$ Follow-Up Inspections - Limited inspections conducted to verify the compliance status in areas that were found to be out of compliance during previous inspections.

While federal EPA employees from headquarters or one of EPA's ten regional offices may conduct compliance inspections, most inspections are conducted by state and local agencies. ${ }^{9}$

\footnotetext{
9 Under Section $\S 3006$ of RCRA, EPA may authorize qualified states to administer and enforce their own hazardous waste program. States with final authorization administer their hazardous waste programs in lieu of EPA's federal program. However, even in states with final authorization, EPA retains the authority to conduct independent inspections and can enforce any provision of an authorized state's approved program, including state requirements that are more stringent than the federal requirements.
} 
RCRA's Compliance Monitoring Strategy requires that all facilities that are permitted to treat, store, or dispose hazardous wastes (facilities known as TSDFs) be inspected at least once every two years and that 20 percent of large quantity generators (LQGs) be inspected each year. Additionally, the Hazardous and Solid Waste Amendments (HSWA) to RCRA require that all federal- and state-operated facilities be inspected annually. Other facilities may be inspected less frequently. When a violation is detected, regulators can choose from a variety of enforcement actions including administrative orders, civil lawsuits, or criminal lawsuits and may conduct additional case development inspections to gather data to support a particular enforcement action.

According to EPA's RCRAInfo database, in 2010 federal and state regulators conducted 32,240 inspections at 24,995 regulated hazardous waste facilities. ${ }^{10}$ While it is difficult to determine exactly the number of facilities regulated under RCRA in 2010, the total number exceeded 700,000. Thus less than 1 in 20 regulated facility was inspected in 2010. Of those facilities that were inspected, the average number of inspections was 1.3 per facility although almost 84 percent (21,103 facilities) were inspected only once that year. Just under 11 percent (2,724 facilities) were inspected on two separate dates while the remaining 6,217 inspections took place at approximately 5 percent $(1,168)$ of inspected facilities. Table 1 shows the breakdown of 2010 inspections by primary inspection type and the type of inspector. ${ }^{11}$ Note that almost 60 percent of inspections are general compliance evaluation inspections and that state regulators conduct over 90 percent of inspections.

Over the five year period of 2006-2010, 150,756 inspections were conducted, or roughly 30,000 per year. These inspections occurred at 80,798 unique facilities, less than one fifth of the regulated universe. Of the inspected facilities, close to 70 percent $(55,800$ facilities) received only one inspection over this time period, while about six percent $(4,507)$ received five or more inspections. Thus there are significant differences in the length of time between inspections across regulated facilities.

\footnotetext{
${ }^{10}$ RCRAInfo is EPA's primary database for all facilities regulated under RCRA. It contains data on all inspections and enforcement actions conducted under RCRA's authority. 11 Over 95 percent of inspections list only one type of inspection and one inspection agency. For the remaining inspections, a primary inspections type and/or primary inspector type was assigned based on author-created hierarchies. Details are available upon request.
} 


\section{Econometric Methodology}

As mentioned in the introduction, most empirical analyses of environmental enforcement use aggregated data (e.g., annual, quarterly, or monthly) to estimate the probability that a facility is inspected during a particular time period or the number of inspections that occur during a that time period. In contrast, this analysis uses data on individual inspections to estimate the length of time between regulatory inspections and the likelihood that a facility that has not been inspected for a given number of days will be inspected the following day. This paper uses a variety of survival or duration models to examine how various explanatory variables affect the "survival" time of subjects in the analysis or the "duration" as a particular type of "spell".12 To conduct a survival or duration analysis one must first identify the universe that one wants to examine and then observe the times at which facilities enter and exit a particular spell. With this information, one can conduct a variety of different analyses to analyze the duration of spells and the ways in which various factors influence the duration. Alternatively one can examine the probability of exiting a spell conditional on having survived for a particular length of time. This probability is known as the hazard rate or hazard function.

Survival models all share the same basic setup. Let $T$ be a non-negative random variable representing the duration of a spell for a particular subject. Then $T$ has an associated density function $f(t)$ and a cumulative distribution function $F(t)$ where $t$ is a realization of $T$. The probability that the spell length is $t$ or longer is given by the survivor function:

$$
S(t)=1-F(t)=\operatorname{Pr}(T>t) .
$$

The probability that one who has survived up to $t$ exits a spell at $t$ (the hazard function) is:

$$
\lambda(t)=\frac{f(t)}{S(t)} .
$$

12 See Wooldridge (2010), Chapter 22 "Duration Models" for a more comprehensive discussion of the use of survival models. 
If $\lambda(t)$ is increasing in $t$, the spell exhibits positive duration dependence. That is, the longer the spell, the higher the probability that one will exit from the spell. One would likely see positive duration dependence if facilities had to be inspected with a particular frequency, e.g. once every two years. The longer the time since the last inspection, the higher the probability of inspection will be. Alternatively, one might see negative duration dependence if the agency engaged in inspection targeting where some facilities were inspected with a high frequency and some inspected with a low frequency. Finally, spells may not exhibit duration dependence if the probability of inspection is constant across time.

The length of a particular spell, $t$, can be written as a function of a vector of explanatory variables $x$ and an error term $\varepsilon$ :

$$
t_{j=} \beta_{0}+x_{j} \beta_{x}+\varepsilon_{j} .
$$

Then the hazard function can be written as:

$$
\lambda_{j}(t)=g\left(t, \beta_{0}+x_{j} \beta_{x}\right),
$$

where the function $g(\cdot)$ depends on the distributional assumptions one makes about $\varepsilon_{j}$. Similarly, the survivor function can be expressed as

$$
S_{j}(t)=h\left(t, \beta_{0}+x_{j} \beta_{x}\right) .
$$

There are two general approaches for incorporating explanatory variables into the analysis, semi-parametric and parametric. ${ }^{13}$ The most common semi-parametric model is

${ }^{13}$ One can also use a non-parametric estimator of the survivor function, the Kaplan-Meier estimator, which does not allow for explanatory variables but instead only uses observed spell durations. This study does not to use such an approach because a preliminary analysis showed that the differences between the Kaplan-Meier estimates for various subsets of the 
the Cox proportional hazard model, which assumes that the hazard rate for an individual subject $j$ can be expressed as:

$$
\lambda\left(t \mid x_{j}\right)=\lambda_{0}(t) e^{x_{j} \beta_{x}}
$$

where $\lambda_{0}(t)$ is a baseline hazard function common to all subjects. The model is then estimated using a partial likelihood estimator that does not require that the baseline hazard be estimated. ${ }^{14}$ The explanatory variables in this model shift the hazard function multiplicatively and the ratio of any two subjects' hazard rates at a given point in time is constant as long as the covariates do not change over time. One advantage of this model is that it allows one to incorporate explanatory variables into the model but does not require one to make assumptions about the baseline hazard model that, if wrong, could result in misleading results. The disadvantage is that there is a loss in efficiency and if one knew the functional form for the baseline hazard one could obtain better estimates of the coefficients. Additionally while one does not have to make assumptions about the baseline hazard, one must assume that all subjects have the same baseline hazard, which could also result in misleading conclusions if the assumption is not correct. To control for multiple spells at individual facilities, the errors can be clustered by facility.

By making an initial assumption about the distribution of the hazard function, parametric models can use the data on spells more efficiently than the Cox model, assuming the distribution is specified correctly. There are a number of commonly used parametric models. The Exponential model is the simplest one as it assumes that the baseline hazard rate is constant, which implies that the underlying cumulative distribution function of the length of spells has an exponential distribution. The Weibull model assumes that the length of spells has a Weibull distribution, which results in a baseline hazard function that can be written as:

$$
\lambda_{0}(t)=\gamma \alpha t^{\alpha-1}
$$

data were statistically significant. Thus the explanatory variables used in the model are important in predicting the duration of spells.

${ }^{14}$ Cox (1972) presents the partial likelihood estimator 
where $\gamma$ and $\alpha$ are non-negative parameters of the model that that will also be estimated. When $\alpha$ equals 1 the Weibull model reduces to the exponential model with a constant hazard rate equal to $\gamma$. If $\alpha$ is greater (less) than one, the hazard rate exhibits positive (negative) duration dependence. Note that in this model, the hazard rate is either monotonically increasing, monotonically decreasing or constant. The Gompertz model also allows for a monotonically increasing or decreasing hazard rate, but unlike the Weibull model, the baseline hazard changes exponentially with time:

$$
\lambda_{0}(t)=\gamma e^{\alpha t} .
$$

Note that this model reduces to the exponential model if $\alpha$ equals 0 . The Log-Logistic model allows for a baseline hazard rate that can both increase and decrease. In this model, the baseline hazard rate is expressed as:

$$
\lambda_{0}(t)=\frac{\gamma \alpha t^{\alpha-1}}{1+\gamma t^{\alpha}} .
$$

When $\gamma$ is less than one, the hazard rate increases up to a certain point in time and then decreases. When $\gamma$ is greater than or equal to one the hazard rate is monotonically decreasing. In all of these models, the explanatory variables serve to shift the hazard function. As with the Cox model, to control for multiple spells at individual facilities, errors are clustered by facility.

The Akaike Information Criterion (AIC) provides a method for determining which of these models provides the best fit. The AIC compares log-likelihoods of the models, adjusting for the number of parameters being fitted. For the parametric survival models, the AIC is defined as:

$$
\mathrm{AIC}=-2 \ln L+2(k+c),
$$


where $\mathrm{k}$ is the number of explanatory variables and $\mathrm{c}$ is the number of model-specific distributional parameters. Thus the AIC captures the trade-off between the complexity of the model and the goodness of fit of the model with a lower AIC indicating a better fit.

\section{Description of the Data}

\section{Data Sources}

Data on facilities subject to RCRA regulation comes from two primary sources, both of which are publicly available on EPA's website: the RCRAInfo database and the Biennial Reporting System (BRS). RCRAInfo contains information on all facilities that are or have been regulated under RCRA Subtitle C, i.e., facilities subject to RCRA hazardous waste regulations. The dataset contains information on facility characteristics, including facility status and regulated activities, and is updated periodically. The dataset also includes information on all inspections and enforcement actions at RCRA regulated facilities. The BRS contains data collected biennially (for odd years) on the generation and management of hazardous waste by facilities.

\section{Universe for Analysis}

This analysis considers all inspections that occurred between January 1, 2000 and December 31, 2010. During this eleven-year time period, 314,776 RCRA inspections were conducted at 90,252 unique facilities. This represents about 12 percent of the over 760,000 facilities in the RCRAInfo database. While the low percentage of facilities that are inspected is partly due to the fact that a number of facilities in the database are inactive, it is also the case that many facilities regulated under RCRA are rarely inspected. In particular, of the over 300,000 facilities identified as conditionally exempt hazardous waste generators, only about a quarter were inspected during the 2000 to 2010 period..$^{15}$

Since the goal of this paper is to better understand the timing of inspections, the study focuses on those facilities that are likely to be inspected with some frequency: large

${ }^{15}$ Conditionally exempt generators generate less than $100 \mathrm{~kg}(220 \mathrm{lb})$ of hazardous waste, or less than $1 \mathrm{~kg}(2.2 \mathrm{lb})$ of acutely hazardous waste, per calendar month. These facilities are subject to many fewer regulations than facilities that generate larger quantities of hazardous waste. 
quantity generators (LQGs) and facilities that store, treat, or dispose hazardous waste (TSDFs). ${ }^{16}$ To ensure that the facilities in the analysis are actively regulated for the entire period of the analysis, the analysis is limited to facilities that consistently reported to the BRS throughout this time period. According to the BRS, 57,545 unique LQGs and TSDFs filed biennial reports between 1999 and 2009.17 Of those facilities, 6,711 filed reports for all of the odd years from 1999 to 2009. Although the requirement that facilities consistently file BRS reports significantly decreases the universe for this analysis, including facilities that are not regulated for the entire period would systematically bias the results of the analysis. Of the 6,711 consistently regulated LQGs and TSDFs, 281 are not inspected during the 2000-2010 period. The 6,430 facilities that are inspected account for 59,480 inspections from 2000 to 2010, almost 20 percent of all RCRA inspections conducted during that period even though they make up only about one percent of the regulated universe.

Approximately 95 percent of the inspections in RCRAInfo identify one type of inspection and one inspecting agency. For the remaining inspections, a primary inspection type and/or primary inspector type was assigned based on author-created hierarchies. ${ }^{18}$ The primary inspection types were then used to identify compliance inspections for the purposes of this analysis. In particular, inspections whose primary type is a facility selfdisclosure, compliance assistance visit, case development inspection, or financial or nonfinancial record review were excluded from the analysis. ${ }^{19}$ When these inspections are excluded, there are 43,559 compliance inspections in the initial dataset.

As discussed in Section 4, the unit of observation for a duration analysis is the spell between inspections, not the inspection itself. The snapspan and stset commands in Stata

\footnotetext{
${ }^{16}$ A large quantity generator is any facility that generates more than $1,000 \mathrm{~kg}(2,200 \mathrm{lb})$ of hazardous waste per calendar month, or more than $1 \mathrm{~kg}(2.2 \mathrm{lb})$ of acutely hazardous waste per calendar month.

${ }^{17}$ Since biennial reports are filed only for the odd years, information from the 1999 reporting cycle is used to infer that a facility was active in 2000 and from the 2009 cycle to infer that a facility was active in 2010.

${ }^{18}$ Details on the hierarchies provided upon request.

${ }^{19}$ Most of these excluded inspections represent a small percentage of total inspections. Financial and non-financial record reviews represent about 20 percent of all inspections, but are excluded because they are not field inspections.
} 
were used to convert the inspection data to spell observations that can be used to conduct the duration analysis. The analysis includes spells that are both left- and right-censored, that is spells that begin before the period of the analysis but end during the analysis and spells that begin during the period of the analysis but end after the period of the analysis. Dropping censored observations might lead to underestimates of spell length if censored spells are likely to be of longer duration than uncensored spells. Including censored spells increases the total number of observations in the dataset to 45,219 . However, because the study includes state-level data, 489 observations from 48 RCRA facilities located in the District of Columbia, Puerto Rico, Guam, and the U.S. Virgin Islands are dropped, leaving a total of 44,730 observations. ${ }^{20}$

\section{Explanatory Variables}

Table 2 presents the explanatory variables used in the analysis along with a brief description of each variable, its mean, and its standard deviation. These data come primarily from RCRAInfo and the BRS. There are three types of explanatory variables: spell-specific data; facility characteristics; and state characteristics. The first set of spell specific-variables identifies the type of inspection that begins the spell. Because compliance evaluation inspections are the most common type of inspection, this category is excluded from the regression and the spell duration of all other types of inspections is compared against the baseline duration of compliance evaluation inspections. There are no ex ante expectations about the signs of the coefficients on these variables. The next set of dummy variables identifies the lead agency in the inspection with the State Lead variable excluded from the regressions. The last two spell-specific variables are Citizen Complaint, which indicates whether the inspection was the result of a citizen compliant and Multimedia

\footnotetext{
${ }^{20}$ Rousseau (2007) runs separate regressions for three different types of inspections: routine, reactive, and project-related. This study separates compliance inspections from non-compliance inspections, but does not further separate compliance inspections for two reasons. First, the RCRAInfo dataset does not provide enough information to separate routine, reactive, and project-related inspections. Second, while there are different types of compliance inspections included in the analysis, the decision of when to inspect and what type of inspection to conduct are likely co-determined. This analysis focuses on estimating the timing of the regulator's decision rather than the type of inspection that the regulator chooses to conduct.
} 
Inspection, which indicates that the inspection included multiple regulatory programs. For these variables there also are no initial expectations as to the sign of the coefficients.

Next consider the facility characteristics. A number of these explanatory variables are fixed and thus are the same across all spell observations at a given facility as well as across the entire period of the analysis. For example TSDF and Commercial TSDF indicate whether the facility treats, stores, or disposes hazardous waste and whether such services are sold commercially by the facility, respectively. Given that RCRA policies require TSDFs to be inspected at least once every two years, one would expect positive coefficients on these variables as a positive coefficient indicates a higher hazard ratio. ${ }^{21}$ The variable Used Oil indicates whether the facility manages used oil in any way. Used oil is regulated separately from other hazardous wastes and suggests, ceteris paribus, a more complex facility. Similarly Multimedia Facility indicates whether the facility is regulated under any other federal EPA programs. Thus one might expect positive coefficients for both of these variables as well.

The next three variables are all based on the primary industrial classification listed for each facility in RCRAInfo. Waste Management is equal to 1 if the facility's primary NAICS is 562; Public Administration is equal to 1 if the facility's primary NAICS is 92; and Manufacturing is equal to 1 if the facility's primary NAICS is 31 through 33. Because federal and state operated facilities are supposed to be inspected at least once a year according to RCRA guidance, one would expect a positive coefficient on Public Administration but there are no prior expectations as to the signs on the other two variables.

The remaining facility characteristics do depend on the date on which the spell starts but they do not vary across the spell itself. Tons Generated, Tons Managed, and Tons Received from Off-Site measure the tons generated, managed, and received from off-site, respectively, in the year prior to the spell's start date. Since BRS data is only reported in odd years, the quantities are interpolated for even years. Thus for a spell that begins in 2002 , the variables are taken from the 2001 BRS while for a spell that begins in 2003, the variables are based on the mean of the quantities in 2001 and 2003. Because the quantities

${ }^{21}$ Positive coefficients correspond with hazard ratios that are greater than 1 (i.e., and increase in the hazard) and negative coefficients correspond with hazard ratios that are less than one. 
of waste generated, managed, and received have a skewed distribution, the model includes the log of tons rather than tons. All of these three variables are expected to have positive coefficients.

Prior Year Inspections, Prior 5 Year Inspections, Prior Year Violations, and Prior 5 Year Violations measure the number of inspections and violations in the 12 months and 60 months immediately prior to the beginning of the spell. Note that for these counts, only compliance inspections are included. However, all violations discovered during the 12month and 60-month time periods are included, regardless of whether those violations were discovered during a compliance inspection. The two violation variables are expected to have positive coefficients as less compliant facilities are more likely to be inspected in the future. Facilities that have been heavily inspected over a five-year period are also expected to continue to be inspected more often. However, controlling for the long-term level of inspection targeting, one might expect inspections in the prior year to increase the duration of the spell, particularly if annual inspections are relatively unlikely.

There are two state characteristics that also depend on the date on which the spell starts: State Inspections and State Violations measure the number of inspections and violations in the state, respectively, for the calendar year prior to the start of the spell. Both of these variables are normalized by the total number of RCRA facilities in the state. State Inspections measures the level of inspection conducted in a state relative to the number of RCRA-regulated entities. If incremental inspection resources are used to increase inspections across all types of facilities, the coefficient on State Inspections should be positive, reflecting shorter spell durations in those states. State Violations is a proxy for the demand in a state for enforcement resources, as regulators will have to expend resources to follow up on detected violations. The coefficient on State Violations is expected to be negative as more violations will likely shift resources away from compliance inspections to following up on the violations. In addition to these two state variables, the regressions includes a set of state dummies to control for other fixed differences in inspection timing across the states. ${ }^{22}$

${ }^{22}$ Ohio is the omitted state. 


\section{Results of the Duration Models}

Cox Proportional Hazard Results

The results of the Cox proportional hazard model are presented in Table 3. To control for multiple spells at the same facility, robust standard errors clustered by facility were estimated. As discussed in Section 4, the Cox proportional hazard model allows explanatory variables to multiplicatively shift the baseline hazard function without requiring one to specify a particular function for that baseline hazard. Figure 1 presents the estimated baseline hazard, which was estimated using non-parametric methods. Note that the hazard function initially increases, then decreases before increasing once again. Recall that an increasing hazard function is consistent with positive duration dependence while a decreasing hazard function shows negative duration dependence.

The coefficients for five of the six inspection types are significant. The four positive and significant coefficients indicate that if the purpose for the inspection that started the spell was a focused inspection, an O\&M inspection, a groundwater inspection, or a corrective action evaluation the hazard rate is higher and thus the duration of the spell shorter than the duration if the inspection that ended the spell was a standard compliance evaluation. For compliance schedule evaluations, the negative and significant coefficient indicates a longer standard compliance evaluation. Three of the six inspector types also have significant coefficients. Thus if the federal EPA or one of its contractors leads the inspection that starts the spell, the duration is longer than if the state leads the inspection. However, if the state has oversight but does not lead, the duration is shorter than if the inspection is led by the standard state regulators. If the inspection that begins the spell is caused by a citizen complaint, the time to the next inspection is longer, as shown by the negative and significant coefficient on Citizen Complaint, perhaps because inspections prompted by citizen complaints are more thorough than standard inspections.

Turning now to the facility-level variables, the positive and significant coefficients on TSDF and Commercial TSDF indicate that the hazard rate is higher for facilities that store, treat, or dispose waste than for generators that do not and thus the time between inspections is shorter. Facilities that are regulated under other EPA programs in addition to RCRA - i.e., Multimedia Facilities - also have a higher hazard ratio than facilities that are only regulated under RCRA. This could be due to the fact that multimedia facilities are 
usually more complex than single media facilities and thus pose a higher potential threat to human health and the environment. Note that both Waste Management and Public Administration also have positive and significant coefficients. The first result is consistent with regulators being more likely to inspect facilities for whom waste management is their primary activity rather than facilities the generate hazardous waste as a by-product of their primary activity. The positive coefficient on Public Administration is consistent with EPA's policy that state and federal facilities be inspected every year. Whether or not a facility is a Manufacturing facility does not appear to have a significant effect on spell duration.

In terms of the time-specific facility variables, all three of the quantity variables have positive and significant coefficients indicating that the larger a facility is, the shorter the time between inspections. This is consistent with inspectors prioritizing inspections at facilities with larger potential impacts on the environment. While the coefficients on both of the facility inspection variables are positive, only the coefficient on Prior Year Inspections is significant. Similarly, although the coefficients on both of the facility violation variables are positive, only the coefficient on Prior 5 Year Violations is significant. The positive coefficients on these variables are consistent with regulatory targeting - that is, regulators targeting facilities with poor compliance records and inspecting them with a higher frequency than generally compliant facilities - and are similar to Rousseau's (2007) findings for Flemish textile plants.

The two State Inspections and State Violations also have significant coefficients. Interestingly, the coefficient on State Inspections is negative indicating longer spells in states with more inspections and the coefficient on State Violations is positive indicating that spells are shorter in states that have more violations per facility. These results are the opposite of expectations, but it is difficult to fully interpret these state variables given that the model also includes state dummy variables as well. Although not reported in Table 3 in the interests of saving space, 30 of the 49 state dummy variables have significant coefficients and they are all jointly significant. Thirteen of the significant coefficients are negative indicating the spells in those states are longer than spells for comparable facilities 
in Ohio and 17 are positive indicating that spells in those states are shorter than spells for comparable facilities in Ohio. ${ }^{23}$

\section{Parametric Model Results}

As discussed in Section 4, by making an initial assumption about the distribution of the hazard function, parametric models can use the data on spells more efficiently than semi-parametric models if the distribution is specified correctly. This study considers four commonly used parametric models: Exponential, Weibull, Gompertz, and Log-Logistic. For all four models, the models include the same explanatory variables that were used in the Cox model presented in Table 2 and estimate robust standard errors clustered by facility. Qualitatively, the estimation results for the Exponential, Weibull, and Gompertz models were all quite consistent. Recall that the Exponential model assumes that the baseline hazard rate is constant while the Weibull and Gompertz models both have two distribution parameters, $\gamma$ and $\alpha$. However, if $\alpha$ equals 1 in the Weibull model it reduces to an Exponential model and if $\alpha$ equals 0 in the Gompertz model, it also reduces to the Exponential model. The results for the Weibull model and the Gompertz model both fail to reject the null hypothesis that the baseline hazard function is constant. Thus only the results for the Exponential model are presented in Table $4 .{ }^{24}$

The results are qualitatively very similar to the results presented in Table 2. There are only three significant changes. First, the coefficient on State Oversight is not significant in the Exponential model, although it was in the Cox model. However, the coefficient is consistently positive. Second, the coefficients on Prior 5 Year Inspections and State Violations are both significant in the Exponential model although neither was in the Cox model. In these cases as well, the signs of the coefficients are the same across the two models. Finally, note that the Exponential model includes a constant term although the Cox model does not. In the Cox model, the baseline hazard model is not estimated directly and thus there is no need to fit a constant term. In the Exponential model, the baseline hazard is estimated to be:

${ }^{23}$ Of course, the number of coefficients that are significant and the signs of those coefficients depend on which state is excluded from the analysis.

${ }^{24}$ The results for the Weibull and Gompertz models are available upon request. 


$$
\lambda_{0}(t)=e^{\alpha}
$$

where $\alpha$ is the constant terms estimated by the model. Thus the baseline hazard in this model is $\mathrm{e}^{-5.67} \square 0.003$, or a 3 in 1000 chance of an inspection each day, regardless of the number of days that have passed since the last inspection.

While the Exponential, Weibull, and Gompertz model are usually expressed in terms of the hazard rate, the Log-Logistic model is most easily interpreted an accelerated timefailure model where:

$$
\ln \left(t_{j}\right)=\beta_{0}+x_{j} \beta_{x}+u_{j}
$$

and $\mathrm{u}_{\mathrm{j}}$ is assumed to follow a logistic distribution. ${ }^{25}$ The estimated coefficients have to be interpreted differently in this model - positive coefficients indicate a longer spell duration while negative coefficients indicate a shorter one. (Recall that the coefficients presented in Tables 3 and 4 change the hazard rate and thus a positive coefficient indicates a higher hazard rate and a shorter spell.)

Table 5 presents the results of the Log-Logistic Model. Allowing for the different interpretations of the coefficients between the Exponential results and the Log-Logistic results, there is one primary difference as well as a number of less significant differences. The most significant difference in the Log-Logistic estimation is that the coefficient on Tons Generated is positive and significant indicating that facilities that generate more waste have a longer time between inspections. This result is contrary to the positive and significant coefficient on Tons Generated in the Exponential regression, which indicates that facilities that generate more waste have a shorter time between inspections. The remaining differences between the two models include coefficients that are significant in the LogLogistic model but not in the Exponential model even though the signs are consistent across the two models (State Oversight, Local Lead, State Contractor, Used Oil, Manufacturing), coefficients that are significant in the Exponential model but not in the

25 The Exponential and Weibull models can also be interpreted as accelerated time-failure models, but the Gompertz cannot. 
Log-Logistic model even though the signs are consistent across the two models (Citizen Complaint, Multimedia Facility, Prior Year Inspections, and Prior 5 Year Violations), and coefficients that are significant in the Exponential model but not in the Log-Logistic model and whose signs are not consistent across the two models (State Inspections and State Violations).

Given the significant differences between the results for the Exponential/Weibull/ Gompertz models compared to the Log-Logistic, one can use the Akaike Information Criterion (AIC) to determine which model is preferable. As discussed at the end of section 4 , the AIC captures the trade-off between the complexity of the model and the goodness of fit of the model with a lower AIC indicating a better fit. As shown in Table 6, the Exponential, Weibull, and Gompertz models have virtually the same AIC and all have a much lower AIC than the Log-Logistic. Since the Exponential model is very straightforward and performs almost as well as the more complicated Weibull and Gompertz models, the Exponential model is used for the next stage of the analysis.

To examine how well the Exponential model predicts inspections, the median predicted spell length for each observation in the duration database is calculated using the estimated parameters of the Exponential model presented in Table 4. The median predicted spell length is the $50^{\text {th }}$ percentile of the survivor function from zero to infinity given each observation's explanatory variables and the estimated model parameters. Figure 2 shows the median predicted spell length plotted against the actual spell length with the dark line indicating the 45-degree line. Note that the Exponential model is not particularly good at predicting relatively long spells, and that the difference between the actual and predicted spells is often well over a year. This point is demonstrated more explicitly in Figure 3, which provides a frequency distribution of the difference between the actual and median predicted spell length. Of the almost 45,000 spells in the analysis, for around 15,000 spells the difference between the actual and the predicted mean spell length is over a year. About fifteen percent of spells are over-estimated by six or more months while over thirty percent of spells are under-estimated by six or more months. Thus while the Exponential model is among the best of the duration models for predicting compliance inspections, there is still a considerable amount of uncertainty about the timing of compliance inspections. Using the Exponential model, it would certainly be difficult to 
predict within a short time frame (one or two months) when a compliance inspection is likely to occur.

\section{Comparison of Duration Model to Other Inspection Models}

Even though the Exponential model does not accurately predict a significant percentage of inspections, it does take into account a significant amount of data on individual inspections. Thus it might be the case that the Exponential model is a better predictor of aggregate inspections than more commonly used models of regulatory inspections. As discussed in the introduction, most empirical analyses of enforcement and compliance generally estimate the likelihood of an inspection for a given time period or the number of inspections for a given time period, with the time period selected based on the type of data available. For RCRA, the most obvious time period is a year since data on waste generation and management is reported annually. To compare the predictions of the Exponential model to annual inspection models, the median predicted spell length was used to create a database of predicted inspection dates that were then aggregated by year to create a count of the number of predicted inspections in each calendar year. Figure 4 plots the predicted inspections using the Exponential median compared to the actual inspections that take place each year. While there are some outliers, note that the model does a pretty good job of predicting the number of annual inspections across the entire support and is particularly accurate as the number of inspections per year increases.

For comparison purposes, a Poisson count model was used to estimate the annual number of inspections conducted at regulated entities. ${ }^{26}$ The database for this analysis contains the annual inspections conducted at each of the 6,382 regulated entities included in the Exponential analysis for each of the eleven years in the study period for a total of 70,202 entity-year observations. ${ }^{27}$ For explanatory variables, the model includes all of the facility-specific and state-specific variables used in the exponential analysis, but since the

\footnotetext{
26 The Poisson regression, unlike a standard OLS regression, takes into account the fact that the number of inspections is a count variable, i.e, a non-negative integer.

27 While there were 6,430 entities in the initial database, recall that the Exponential model uses state-specific data, and thus 48 entities in DC, Puerto Rico, Guam, and the Virgin Islands were dropped from the analysis.
} 
analysis is an annual one, none of the spell-specific variables are included..$^{28}$ The results of the regression are presented in Table 7. Figure 5 shows the predicted number of inspections from the Poisson model plotted against the actual inspections that take place each year. Comparing to Figure 5 to Figure 4, note that the Poisson model appears to under-predict the number of inspections when the actual count is below 40 and overpredict the number when the actual count is 50 or more.

To better compare these two models, Table 8 compares the accuracy of the models across various segments of the universe. ${ }^{29}$ First note that the Poisson model is better at predicting which facilities will have no inspections, correctly predicting no inspections 81 percent of the time compared the Exponential model's 73 percent correct predictions. However, the Poisson model estimates a higher mean number of predicted inspections for facilities in this category than the Exponential models does - thus if one cares primarily about the total predicted number of inspections, the Exponential model performs better than the Poisson model for this category. For facilities with only one inspection in a given year, the Poisson model also is correct a higher percentage of the time - 37 percent versus 32 percent for the Exponential model. Both models under-predict the mean number of inspections, although for this category the Poisson model is closer to the actual mean than the Exponential model is. For all of the remaining categories, the Exponential model does a better job of correctly predicting the number of inspections both in terms of the percentage correct and the mean number of inspections. If one were to consider all facilities with at least one inspection together, for that group the Exponential model also has the highest number of correct predictions and is closer to the true mean. Thus which model would be more appropriate for predicting annual inspections depends on the question the researcher wants to answer and whether it is more important to correctly identify facilities that are inspected or are not inspected.

${ }^{28}$ In the Exponential analysis, there is a set of variables capturing the number of inspections and violations conducted at the facility in the 12 months and 5 years prior to the start of each spell. For the Poisson analysis similar variables are constructed for the 12 months and 5 years prior to the start of each calendar year.

${ }^{29}$ Although the Poisson model takes into account the integer nature of the inspection variable, the prediction the model generates is the estimated mean of the number of inspections. Therefore the Poisson predictions are rounded to the nearest integer to identify "correct predictions." 
Because many inspection models examine not the number of inspections, but rather whether any inspections are conducted over a certain period, a Probit analysis was conducted to estimate the probability that at least one inspection took place in a calendar year. Table 9 presents the results of this analysis. The same facility-specific and statespecific explanatory variables are used in this analysis as in the analysis presented in Table 8 , but the dependent variable is a binary variable equal to 1 if any inspection occurred at the regulated entity in a given year. To compare the results of the Probit model to the Exponential model, Table 10 compares the predictions of each model to the actual inspections. ${ }^{30}$ As shown, the Probit model correctly predicts 40,083 of the 43,968 entityyear observations where there is no inspection while the Exponential model correctly predicts only 32,235 of these observations. Thus the Probit model is a better predictor of situations where there is no inspection. Once again Exponential model is a better predictor of inspections, correctly predicting 12,863 of the 26,234 observations where an inspection occurs compared to 11,107 predicted by the Probit model. Overall, the Probit model is correct approximately 73 percent of the time while the Exponential model is correct about 64 percent of the time. However, which model is a "better" predictor depends on the relative importance of Type I and Type II errors. The Probit model results in 21.5 percent Type II errors (i.e. false negatives where no inspection is predicted even though there actually is an inspection) but only 5.5 percent Type I errors (i.e. false positives where an inspection is predicted even though there is no inspection). On the other hand the Exponential model results in only 19 percent Type II errors, but 16.7 percent Type I errors.

\section{Conclusions}

The primary objective of this paper is to examine the timing of environmental compliance inspections and determine the extent to which such inspections can be predicted. The analysis considered a number of different duration models that use information on individual inspections, facility characteristics, and state factors to predict the timing of compliance inspections. Of the models considered, the Exponential model

\footnotetext{
30 Because the Probit model predicts a probability of inspection, for any observation where the predicted probability of an inspection was greater than 0.5 , the Probit model is credited with a predicted inspection.
} 
provides the best balance in terms of the explanatory power of the model and the simplicity of the model. However, even when one uses detailed information about individual inspections and facility characteristics to predict inspection dates, the Exponential model is not able to accurately predict a significant percentage of inspections. Thus there remains significant uncertainty about the likely timing compliance inspections in the RCRA program, and the assumption that such inspections are probabilistic appears to be valid.

A secondary objective of this paper is to determine the extent to which using detailed information on individual inspections and the Exponential model can improve empirical predictions of the timing of inspections. If the goal is to estimate the annual number of inspections, neither the Exponential model or the Poisson model is a clear winner. While the Poisson model is better at predicting which facilities have no or one inspection, the Exponential model is better at predicting multiple inspections. Also, the Exponential model is better at predicting the mean number of inspections for facilities that are inspected. Similarly, if the focus is on whether any inspection occurred in a given time period (rather than the number of inspections during that time period), the benefits of using the Exponential model depend on the nature of the questions to be answered. While the Exponential model performs better than the Probit model in predicting which entities will be inspected, it also results in a higher number of "false positives," that is predicting an inspection when no inspection actually occurs. Thus which model is a better model depends on what question the research wants to answer and whether Type I or Type II errors are more important. 


\section{References:}

Becker, Gary S. 1968. "Crime and Punishment: An Economic Approach." Journal of Political Economy, 76:169-172.

Cohen, Mark. 1999. "Monitoring and Enforcement of Environmental Policy" in International Yearbook of Environmental and Resource Economics, III, Edited by Tom Tietenberg and Henk Folmer, Cheltenham, UK: Edward Elgar Publishing.

Cox, D. R. 1972. "Regression Models and Life-Tables," Journal of the Royal Statistical Society 34: $187-220$.

Earnhart, Dietrich. 2004. "Regulatory Factors Shaping Environmental Performance at Publicly Owned Treatment Plants," Journal of Environmental Economics and Management 48: 655-81.

Friesen, Lana. 2003. "Targeting Enforcement to Improve Compliance with Environmental Regulations," Journal of Environmental Economics and Management 46:72-85.

Glicksman, R., and Dietrich Earnhart. 2007. "The Comparative Effectiveness of Government Interventions on Environmental Performance in the Chemical Industry," Stanford Environmental Law Journal 26: 317-71.

Gray, Wayne and Mary Deily. 1996. "Compliance and Enforcement: Air Pollution Regulation in the U.S. Steel Industry," Journal of Environmental Economics and Management 31: 96-111.

Gray, Wayne and Ron Shadbegian. 2005. "When and Why Do Plants Comply? Paper Mills in the 1980s," Law and Policy 27: 238-61.

Gray, Wayne B. and Jay P. Shimshack. 2011. "The Effectiveness of Environmental Monitoring and Enforcement: A Review of the Empirical Evidence," Review of Environmental Economics and Policy 5:3-24.

Harford, John and Winston Harrington. 1991. "A Reconsideration of Enforcement Leverage When Penalties Are Restricted," Journal of Public Economics 45:391-195.

Harrington, Winston. 1988. "Enforcement Leverage When Penalties Are Restricted," Journal of Public Economics 37:29-53.

Helland, Eric. 1998. "The Enforcement of Pollution Control Laws: Inspections, Violations, and Self-Reporting," Review of Economics and Statistics 80:141-153.

Heyes, Anthony. 2000. "Implementing Environmental Regulation: Enforcement and Compliance," Journal of Regulatory Economics, 17(2):107-129. 
Nadeau, Louis W. 1997. "EPA Effectiveness at Reducing the Duration of Plant-Level Noncompliance," Journal of Environmental Economics and Management, 34(1):5478.

Nyborg, Karine and Kjetil Telle. 2006. “Firms' Compliance to Environmental Regulation: Is There Really a Paradox?," Environmental and Resource Economics 35(1):1-18.

Polinsky, Mitchell and Steven Shavell. 2000. "The Economic Theory of Public Enforcement of Law," Journal of Economic Literature, 38(1):45-76.

Raymond, Mark. 1999. “Enforcement Leverage When Penalties Are Restricted: A Reconsideration Under Asymmetric Information," Journal of Public Economics 73: 289-295.

Rousseau, Sandra. 2007. "Timing of Environmental Inspections: Survival of the Compliant," Journal of Regulatory Economics 32:17-36.

Russell, Clifford S., Winston Harrington and William J. Vaughan. 1986. Economic Models of Monitoring and Enforcement: Enforcing Pollution Control Laws, Washington, D.C: Resources for the Future.

Stafford, Sarah. 2007. "Should You Turn Yourself In? The Consequences of Environmental Self-Policing," Journal of Policy Analysis and Management 26:305-326

Stafford, Sarah. 2002. "The Effect of Punishment on Firm Compliance with Hazardous Waste Regulations," Journal of Environmental Economics and Management 44:290308.

Steinway, Daniel M. 2009. "Fundamentals of Environmental Law," in Environmental Law Handbook Ed. by Thomas F.P. Sullivan. Government Institutes: Lanham, MD.

Wooldridge, Jeffrey. 2010. Econometric Analysis of Cross Section and Panel Data, $2^{\text {nd }}$ edition. Cambridge, MA: The MIT Press. 
Table 1: Breakdown of 2010 RCRA Inspections

\begin{tabular}{|l|c|c|}
\hline Primary Inspection Type & Number of Inspections & Percent of Inspections \\
\hline Compliance Evaluation Inspection & 19,492 & $60 \%$ \\
Focused Compliance Inspection & 3,819 & $12 \%$ \\
Non-Financial Record Review & 2,856 & $9 \%$ \\
Compliance Assistance Visit & 962 & $3 \%$ \\
Financial Record Review & 1,066 & $3 \%$ \\
Other & 4,045 & $13 \%$ \\
\hline Inspector Type & Number of Inspections & Percent of Inspections \\
\hline State & 29,763 & $92 \%$ \\
EPA & 1,608 & $5 \%$ \\
State Contractor & 466 & $1 \%$ \\
EPA Contractor & 381 & $1 \%$ \\
Other & 22 & $<1 \%$ \\
\hline
\end{tabular}


Table 2: Description of Explanatory Variables

\begin{tabular}{|c|c|c|c|}
\hline Variable Name & Description & Mean & SD \\
\hline \multicolumn{4}{|l|}{\begin{tabular}{|l|} 
Spell-Specific Data \\
\end{tabular}} \\
\hline Compliance Evaluation* & \multirow{7}{*}{$\begin{array}{l}\text { Dummy variables indicating the type } \\
\text { of inspection that begins the spell. }\end{array}$} & 0.70 & 0.46 \\
\hline \begin{tabular}{|l|} 
Focused Inspection \\
\end{tabular} & & 0.17 & 0.38 \\
\hline O\&M Inspection & & & \\
\hline $\begin{array}{l}\text { Compliance Schedule } \\
\text { Evaluation }\end{array}$ & & 0.06 & 0.24 \\
\hline Follow-up Inspection & & 0.02 & 0.14 \\
\hline Groundwater Monitoring & & 0.01 & 0.11 \\
\hline Corrective Action Eval. & & 0.01 & 0.10 \\
\hline \begin{tabular}{|l|} 
EPA Lead \\
\end{tabular} & \multirow{7}{*}{$\begin{array}{l}\text { Dummy variables indicating the type } \\
\text { of inspector at the inspection that } \\
\text { begins the spell. }\end{array}$} & 0.07 & 0.26 \\
\hline \begin{tabular}{|l} 
State Lead* \\
\end{tabular} & & 0.90 & 0.30 \\
\hline EPA Oversight & & 0.00 & 0.05 \\
\hline State Oversight & & 0.00 & 0.01 \\
\hline Local Lead & & 0.00 & 0.05 \\
\hline EPA Contractor & & 0.00 & 0.07 \\
\hline State Contractor & & 0.01 & 0.12 \\
\hline Citizen Complaint & $\begin{array}{l}=1 \text { if the beginning inspection is due to } \\
\text { a citizen compliant. }\end{array}$ & 0.01 & 0.11 \\
\hline Multimedia Inspection & $\begin{array}{l}=1 \text { if the beginning inspection includes } \\
\text { other EPA programs. }\end{array}$ & 0.03 & 0.16 \\
\hline \multicolumn{4}{|l|}{ Facility Characteristics } \\
\hline TSDF & $\begin{array}{l}=1 \text { if the facility treats, stores, or } \\
\text { disposes of hazardous waste. }\end{array}$ & 0.37 & 0.48 \\
\hline Commercial TSDF & $\begin{array}{l}=1 \text { if the facility is sells treatment, } \\
\text { storage, or disposal services. }\end{array}$ & 0.24 & 0.43 \\
\hline Used Oil Facility & $=1$ if the facility manages used oil. & 0.12 & 0.33 \\
\hline Multimedia Facility & $\begin{array}{l}=1 \text { if the facility is regulated under } \\
\text { other EPA programs. }\end{array}$ & 0.89 & 0.32 \\
\hline Waste Management & $\begin{array}{l}=1 \text { if the facility's main industry is } \\
\text { waste management. }\end{array}$ & 0.25 & 0.43 \\
\hline Public Administration & $\begin{array}{l}=1 \text { if the facility's main industry is } \\
\text { public administration. }\end{array}$ & 0.05 & 0.22 \\
\hline Manufacturing & $\begin{array}{l}=1 \text { if the facility's main industry is } \\
\text { manufacturing. }\end{array}$ & 0.58 & 0.49 \\
\hline Tons Generated & $\begin{array}{l}=\log \text { of tons of waste generated in the } \\
\text { calendar year prior to the start of the } \\
\text { spell. }\end{array}$ & 2.84 & 8.38 \\
\hline Tons Managed & $\begin{array}{l}=\log \text { of tons of waste managed in } \\
\text { calendar year prior to the start of the } \\
\text { spell. }\end{array}$ & -10.63 & 10.06 \\
\hline
\end{tabular}




\begin{tabular}{|c|c|c|c|}
\hline Variable Name & Description & Mean & SD \\
\hline $\begin{array}{l}\text { Tons Received from } \\
\text { Offsite }\end{array}$ & $\begin{array}{l}=\log \text { of tons of waste received for } \\
\text { management in the calendar year prior } \\
\text { to the start of the spell. }\end{array}$ & -9.54 & 10.89 \\
\hline Prior Year Inspections & $\begin{array}{l}=\text { number of inspections in the year } \\
\text { prior to the start of the spell. }\end{array}$ & 6.20 & 15.17 \\
\hline Prior 5 Year Inspections & $\begin{array}{l}=\text { number of inspections in the } 5 \text { years } \\
\text { prior to the start of the spell. }\end{array}$ & 25.55 & 60.94 \\
\hline Prior Year Violations & $\begin{array}{l}=\text { number of violations in the year } \\
\text { prior to the start of the spell. }\end{array}$ & 2.78 & 13.56 \\
\hline Prior 5 Year Violations & $\begin{array}{l}=\text { number of violations in the } 5 \text { years } \\
\text { prior to the start of the spell. }\end{array}$ & 15.73 & 60.42 \\
\hline \multicolumn{4}{|l|}{ State Characteristics } \\
\hline State Inspections & $\begin{array}{l}\text { = total state inspections in the } \\
\text { calendar year prior to the start of the } \\
\text { spell, normalized by the number of } \\
\text { RCRA facilities. }\end{array}$ & 0.03 & 0.03 \\
\hline State Violations & $\begin{array}{l}=\text { total state violations in the calendar } \\
\text { year prior to the start of the spell, } \\
\text { normalized by the number of RCRA } \\
\text { facilities. }\end{array}$ & 0.05 & 0.04 \\
\hline State Dummies & $\begin{array}{l}=\text { set of binary indicator variables for } \\
\text { each of the } 50 \text { states, excluding Ohio }\end{array}$ & N/A & N/A \\
\hline
\end{tabular}

${ }^{*}$ Category excluded from the regression. 
Table 3: Results of the Cox Proportional Hazard Model

\begin{tabular}{|c|c|c|c|}
\hline Variable & Coefficient & Standard Error $\dagger$ & Hazard Ratio \\
\hline Focused Inspection & $0.556^{* *}$ & 0.053 & 1.744 \\
\hline O\&M Inspection & $0.743^{* *}$ & 0.071 & 2.103 \\
\hline Compliance Schedule Evaluation & $-0.226^{* *}$ & 0.031 & 0.797 \\
\hline Follow-up Inspection & -0.004 & 0.047 & 0.996 \\
\hline Groundwater Monitoring & $0.534^{* *}$ & 0.056 & 1.704 \\
\hline Corrective Action Eval. & $0.793^{* *}$ & 0.102 & 2.210 \\
\hline EPA Lead & $-0.101^{* *}$ & 0.026 & 0.904 \\
\hline EPA Oversight & 0.039 & 0.180 & 1.040 \\
\hline State Oversight & $0.443^{*}$ & 0.236 & 1.558 \\
\hline Local Lead & 0.029 & 0.079 & 1.029 \\
\hline EPA Contractor & $-0.323^{* *}$ & 0.109 & 0.724 \\
\hline State Contractor & -0.022 & 0.074 & 0.978 \\
\hline Citizen Complaint & $-0.265^{* *}$ & 0.065 & 0.767 \\
\hline Multimedia Inspection & 0.006 & 0.036 & 1.006 \\
\hline TSDF & $0.481^{* *}$ & 0.055 & 1.618 \\
\hline Commercial TSDF & $0.216^{* *}$ & 0.089 & 1.241 \\
\hline Used Oil Facility & 0.064 & 0.082 & 1.066 \\
\hline Multimedia Facility & $0.127^{* *}$ & 0.038 & 1.136 \\
\hline Waste Management & $0.362^{* *}$ & 0.100 & 1.436 \\
\hline Public Administration & $0.371^{* *}$ & 0.073 & 1.449 \\
\hline Manufacturing & -0.028 & 0.042 & 0.972 \\
\hline Tons Generated & $0.009^{* *}$ & 0.002 & 1.010 \\
\hline Tons Managed & $0.007^{* *}$ & 0.002 & 1.007 \\
\hline Tons Received from Offsite & $0.013^{* *}$ & 0.004 & 1.013 \\
\hline Prior Year Inspections & $0.041^{* *}$ & 0.004 & 1.042 \\
\hline Prior 5 Year Inspections & 0.001 & 0.001 & 1.001 \\
\hline Prior Year Violations & 0.001 & 0.001 & 1.001 \\
\hline Prior 5 Year Violations & $0.001^{* *}$ & 0.000 & 1.001 \\
\hline State Inspections & $-6.047^{* *}$ & 1.223 & 0.002 \\
\hline State Violations & 0.088 & 0.290 & 1.092 \\
\hline
\end{tabular}

State dummies are included in the regression but are omitted from the table.

† Standard errors are clustered by facility; ${ }^{* *}$ Significant at the $1 \%$ level; *Significant at the $5 \%$ level. 
Table 4: Results of the Exponential Model

\begin{tabular}{|lccc|}
\hline Variable & Coefficient & Standard Error $\dagger$ & Hazard Ratio \\
\hline Focused Inspection & $0.566^{* *}$ & 0.052 & 1.762 \\
O\&M Inspection & $0.741^{* *}$ & 0.071 & 2.099 \\
Compliance Schedule Evaluation & $-0.245^{* *}$ & 0.031 & 0.783 \\
Follow-up Inspection & 0.011 & 0.047 & 1.011 \\
Groundwater Monitoring & $0.537^{* *}$ & 0.056 & 1.711 \\
Corrective Action Eval. & $0.769^{* *}$ & 0.105 & 2.157 \\
EPA Lead & $-0.095^{* *}$ & 0.026 & 0.910 \\
EPA Oversight & 0.016 & 0.199 & 1.016 \\
State Oversight & 0.275 & 0.229 & 1.316 \\
Local Lead & -0.002 & 0.078 & 0.998 \\
EPA Contractor & $-0.281^{* *}$ & 0.110 & 0.755 \\
State Contractor & -0.092 & 0.074 & 0.912 \\
Citizen Complaint & $-0.275^{* *}$ & 0.066 & 0.759 \\
Multimedia Inspection & 0.019 & 0.036 & 1.020 \\
TSDF & $0.497^{* *}$ & 0.055 & 1.643 \\
Commercial TSDF & $0.222^{* *}$ & 0.089 & 1.249 \\
Used Oil Facility & 0.061 & 0.082 & 1.063 \\
Multimedia Facility & $0.129^{* *}$ & 0.038 & 1.137 \\
Waste Management & $0.361^{* *}$ & 0.102 & 1.434 \\
Public Administration & $0.370^{* *}$ & 0.073 & 1.448 \\
Manufacturing & -0.030 & 0.043 & 0.971 \\
Tons Generated & $0.009^{* *}$ & 0.002 & 1.009 \\
Tons Managed & $0.007^{* *}$ & 0.002 & 1.007 \\
Tons Received from Offsite & $0.012^{* *}$ & 0.004 & 1.013 \\
Prior Year Inspections & $0.037^{* *}$ & 0.004 & 1.038 \\
Prior 5 Year Inspections & $0.002^{* *}$ & 0.001 & 1.002 \\
Prior Year Violations & 0.000 & 0.001 & 1.000 \\
Prior 5 Year Violations & $0.001^{* *}$ & 0.000 & 1.001 \\
State Inspections & $-2.844^{* *}$ & 1.183 & 0.058 \\
State Violations & $0.461^{*}$ & 0.279 & 1.586 \\
Constant & -5.674 & 0.192 & $\mathrm{NA}$ \\
\hline Stad4 & & & \\
\hline
\end{tabular}

State dummies are included in the regression but are omitted from the table.

† Standard errors are clustered by facility; ${ }^{* *}$ Significant at the $1 \%$ level; *Significant at the $5 \%$ level. 
Table 5: Results of the Log-Logistic Model

\begin{tabular}{|c|c|c|}
\hline Variable & Coefficient & Standard Error $\dagger$ \\
\hline Focused Inspection & $-0.393^{* *}$ & 0.052 \\
\hline O\&M Inspection & $-0.458^{* *}$ & 0.123 \\
\hline Compliance Schedule Evaluation & $0.275^{* *}$ & 0.037 \\
\hline Follow-up Inspection & 0.020 & 0.052 \\
\hline Groundwater Monitoring & $-0.464^{* *}$ & 0.096 \\
\hline Corrective Action Eval. & $-0.572^{* *}$ & 0.199 \\
\hline EPA Lead & $0.098^{* *}$ & 0.030 \\
\hline EPA Oversight & -0.126 & 0.200 \\
\hline State Oversight & $-2.526^{* *}$ & 0.258 \\
\hline Local Lead & $0.348^{* *}$ & 0.085 \\
\hline EPA Contractor & $0.216^{*}$ & 0.114 \\
\hline State Contractor & $0.350^{*}$ & 0.064 \\
\hline Citizen Complaint & 0.056 & 0.080 \\
\hline Multimedia Inspection & -0.018 & 0.049 \\
\hline TSDF & $-0.362^{* *}$ & 0.047 \\
\hline Commercial TSDF & $-0.109^{*}$ & 0.061 \\
\hline Used Oil Facility & $-0.137^{* *}$ & 0.063 \\
\hline Multimedia Facility & -0.037 & 0.030 \\
\hline Waste Management & $-0.141^{* *}$ & 0.055 \\
\hline Public Administration & $-0.275^{* *}$ & 0.061 \\
\hline Manufacturing & $-0.064^{* *}$ & 0.027 \\
\hline Tons Generated & $0.033^{* *}$ & 0.001 \\
\hline Tons Managed & $-0.011^{* *}$ & 0.001 \\
\hline Tons Received from Offsite & $-0.005^{* *}$ & 0.002 \\
\hline Prior Year Inspections & 0.016 & 0.020 \\
\hline Prior 5 Year Inspections & $-0.120^{*}$ & 0.011 \\
\hline Prior Year Violations & -0.003 & 0.002 \\
\hline Prior 5 Year Violations & -0.001 & 0.001 \\
\hline State Inspections & -0.097 & 0.728 \\
\hline State Violations & 0.544 & 0.426 \\
\hline Constant & $6.961^{* *}$ & 0.235 \\
\hline Gamma & $0.287^{* *}$ & 0.008 \\
\hline
\end{tabular}

State dummies are included in the regression but are omitted from the table.

† Standard errors are clustered by facility; ${ }^{* *}$ Significant at the $1 \%$ level; *Significant at the $5 \%$ level. 
Table 6: AIC Values for the Parametric Models

\begin{tabular}{|lcc|}
\hline Model & Log Likelihood & AIC \\
\hline Cox Proportional Hazards & $-340,034$ & 680,225 \\
Exponential & 28,311 & $-56,462$ \\
Weibull & 28,317 & $-56,473$ \\
Gompertz & 28,390 & $-56,619$ \\
Log-Logistic & 1,157 & $-2,152$ \\
\hline
\end{tabular}

Table 7: Results of the Tobit and Poisson Model of Annual Inspections

\begin{tabular}{|lcccc|}
\hline & \multicolumn{2}{c}{ Tobit Model } & \multicolumn{2}{c|}{ Poisson Model } \\
\cline { 2 - 5 } Explanatory Variables & Coefficient & $\begin{array}{c}\text { Standard } \\
\text { Error } \dagger\end{array}$ & Coefficient & $\begin{array}{c}\text { Standard } \\
\text { Error }\end{array}$ \\
\hline TSDF & $0.304^{* *}$ & 0.069 & $0.530^{* *}$ & 0.058 \\
Commercial TSDF & $0.323^{* *}$ & 0.091 & $0.228^{* *}$ & 0.090 \\
Used Oil Facility & $0.337^{* *}$ & 0.140 & 0.116 & 0.092 \\
Multimedia & $0.156^{* *}$ & 0.036 & $0.161^{* *}$ & 0.042 \\
Waste Management & -0.001 & 0.098 & $0.307^{* *}$ & 0.112 \\
Public Administration & $0.624^{* *}$ & 0.081 & $0.466^{* *}$ & 0.081 \\
Manufacturing & 0.043 & 0.033 & -0.061 & 0.045 \\
Prior Year Tons Generated & 0.004 & 0.010 & $0.037^{* *}$ & 0.006 \\
Prior Year Tons Managed & $0.005^{* *}$ & 0.002 & $0.009^{* *}$ & 0.002 \\
Prior Year Tons Received & & & & \\
from Offsite & $0.012^{* *}$ & 0.003 & $0.015^{* *}$ & 0.004 \\
Prior Year Inspections & $0.460^{* *}$ & 0.077 & $0.035^{* *}$ & 0.006 \\
Prior 5 Year Inspections & $0.075^{* *}$ & 0.011 & $0.004^{* *}$ & 0.001 \\
Prior Year Violations & $-0.015^{* *}$ & 0.003 & 0.0002 & 0.0001 \\
Prior 5 Year Violations & -0.0003 & 0.0004 & $0.0003^{* *}$ & 0.0001 \\
Prior Year State Inspections & $3.558^{* *}$ & 1.250 & 0.222 & 1.392 \\
Prior Year State Violations & -0.474 & 0.371 & -0.259 & 0.216 \\
Constant & $-1.914^{* *}$ & 0.137 & $-1.034^{* *}$ & 0.104 \\
\hline
\end{tabular}

State dummies are included in the regression but are omitted from the table.

† Standard errors are clustered by facility; ${ }^{* *}$ Significant at the $1 \%$ level; *Significant at the $5 \%$ level. 
Table 8: Comparison of Exponential and Poisson Predictions

\begin{tabular}{|c|c|c|c|c|c|c|}
\hline \multirow{2}{*}{$\begin{array}{l}\text { Actual Number } \\
\text { of Annual } \\
\text { Inspections }\end{array}$} & \multirow[b]{2}{*}{$\begin{array}{c}\text { Number } \\
\text { of Obs. }\end{array}$} & \multicolumn{2}{|c|}{$\begin{array}{c}\text { Number of Correct } \\
\text { Predictions }\end{array}$} & \multicolumn{3}{|c|}{ Mean Number of Inspections } \\
\hline & & $\begin{array}{c}\text { Exponential } \\
\text { Model }\end{array}$ & $\begin{array}{c}\text { Poisson } \\
\text { Model }\end{array}$ & Actual & $\begin{array}{c}\text { Exponential } \\
\text { Model }\end{array}$ & $\begin{array}{c}\text { Poisson } \\
\text { Model }\end{array}$ \\
\hline Not Inspected & 43,968 & $\begin{array}{l}32,235 \\
(73 \%)\end{array}$ & $\begin{array}{l}35,438 \\
(81 \%)\end{array}$ & 0 & 0.30 & 0.41 \\
\hline One & 19,731 & $\begin{array}{c}6,471 \\
(32 \%)\end{array}$ & $\begin{array}{l}7,352 \\
(37 \%)\end{array}$ & 1 & 0.52 & 0.61 \\
\hline Two to Five & 6,074 & $\begin{array}{l}1,608 \\
(26 \%)\end{array}$ & $\begin{array}{c}717 \\
(12 \%)\end{array}$ & 2.41 & 1.49 & 1.17 \\
\hline Six to Ten & 182 & $\begin{array}{c}48 \\
(26 \%)\end{array}$ & $\begin{array}{c}5 \\
(3 \%)\end{array}$ & 7.26 & 6.57 & 2.94 \\
\hline Eleven to Twenty & 115 & $\begin{array}{c}40 \\
(35 \%)\end{array}$ & $\begin{array}{c}0 \\
(0 \%)\end{array}$ & 13.90 & 13.17 & 4.87 \\
\hline More than 20 & 132 & $\begin{array}{c}37 \\
(28 \%)\end{array}$ & $\begin{array}{c}1 \\
(1 \%)\end{array}$ & 38.65 & 30.16 & 33.05 \\
\hline Overall & 70,202 & $\begin{array}{l}40,439 \\
(58 \%)\end{array}$ & $\begin{array}{l}43,513 \\
(62 \%)\end{array}$ & 0.60 & 0.58 & 0.60 \\
\hline
\end{tabular}

Table 9: Results of the Probit Model of Annual Inspections

\begin{tabular}{|lcc|}
\hline Variable & Coefficient & Standard Error $\dagger$ \\
\hline TSDF & $0.536^{* *}$ & 0.037 \\
Commercial TSDF & $0.161^{* *}$ & 0.059 \\
Used Oil Facility & 0.049 & 0.050 \\
Multimedia & $0.079^{* *}$ & 0.019 \\
Waste Management & 0.020 & 0.044 \\
Public Administration & $0.443^{* *}$ & 0.044 \\
Manufacturing & 0.016 & 0.017 \\
Prior Year Tons Generated & $0.019^{* *}$ & 0.003 \\
Prior Year Tons Managed & $0.004^{* *}$ & 0.001 \\
Prior Year Tons Received from Offsite & $0.014^{* *}$ & 0.002 \\
Prior Year Inspections & $-0.115^{* *}$ & 0.010 \\
Prior 5 Year Inspections & $0.074^{* *}$ & 0.004 \\
Prior Year Violations & $0.001^{*}$ & 0.0007 \\
Prior 5 Year Violations & -0.0002 & 0.0002 \\
Prior Year State Inspections & $6.359^{* *}$ & 0.696 \\
Prior Year State Violations & -0.182 & 0.200 \\
Constant & $-0.474^{* *}$ & 0.065 \\
\hline
\end{tabular}

State dummies are included in the regression but are omitted from the table.

† Standard errors are clustered by facility; ${ }^{* *}$ Significant at the $1 \%$ level; *Significant at the $5 \%$ level. 
Table 10: Comparison of Probit and Exponential Model Results

\begin{tabular}{|c|c|l|l|}
\hline Status & $\begin{array}{c}\text { Actual } \\
\text { Observations }\end{array}$ & Probit Model Predictions & \multicolumn{1}{c|}{$\begin{array}{c}\text { Exponential Model } \\
\text { Predictions }\end{array}$} \\
\hline $\begin{array}{c}\text { Entity Not } \\
\text { Inspected }\end{array}$ & 43,968 & Not Insp.: $40,083(57.1 \%)$ & Not Insp.: $32,235(45.9 \%)$ \\
\cline { 3 - 4 } $\begin{array}{c}\text { Entity } \\
\text { Inspected }\end{array}$ & 26,234 & Inspected: 3,885 (5.5\%) & Inspected: $11,733(16.7 \%)$ \\
\cline { 3 - 4 } & & Inspected: $11,107(15.8 \%)$ & Inspected: $12,863(18.3 \%)$ \\
\hline
\end{tabular}


Figure 1: Estimated Baseline Hazard for the Cox Proportional Hazard Model

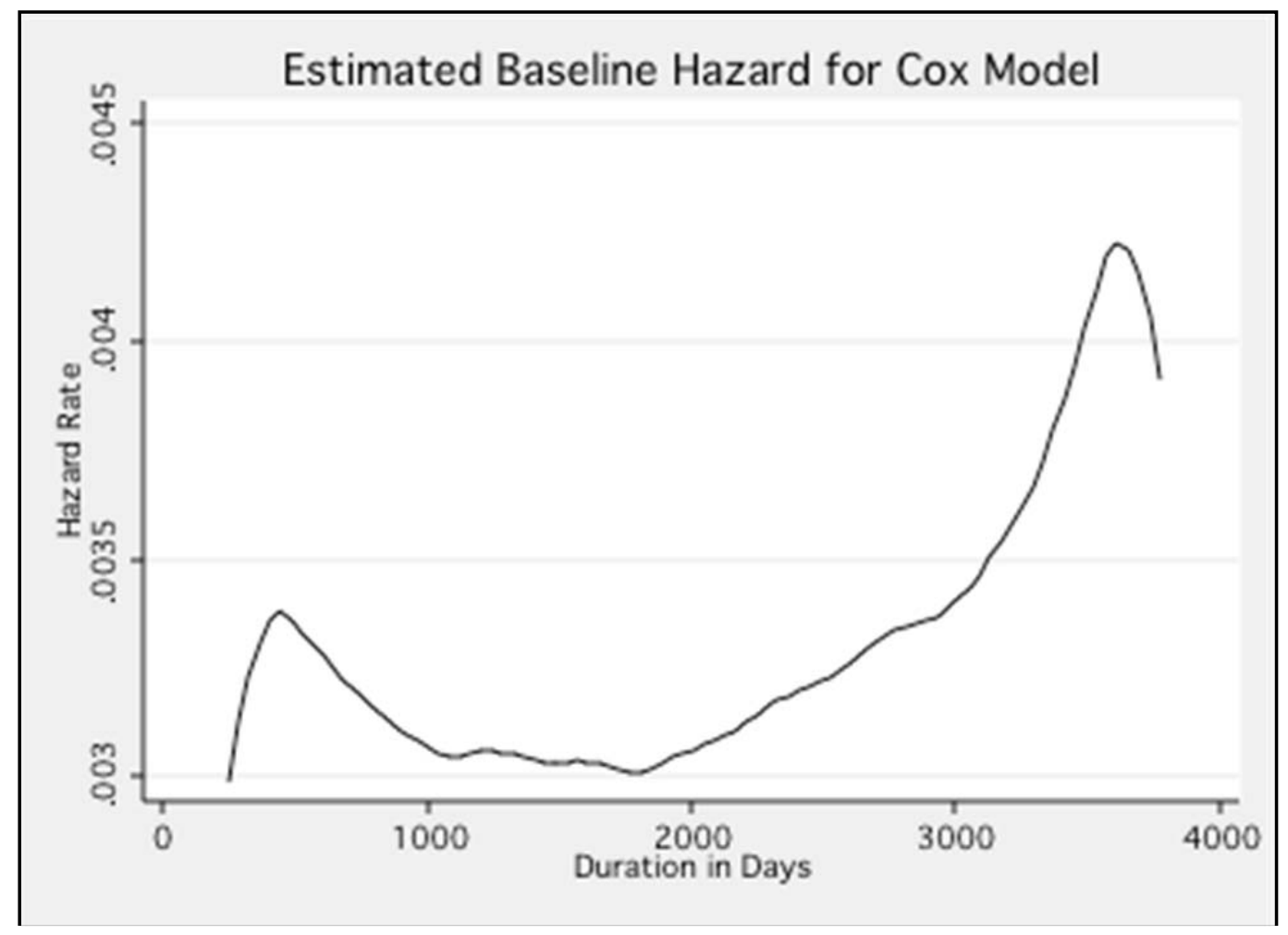

Figure 2: Median Predicted Spell Length from Exponential Model

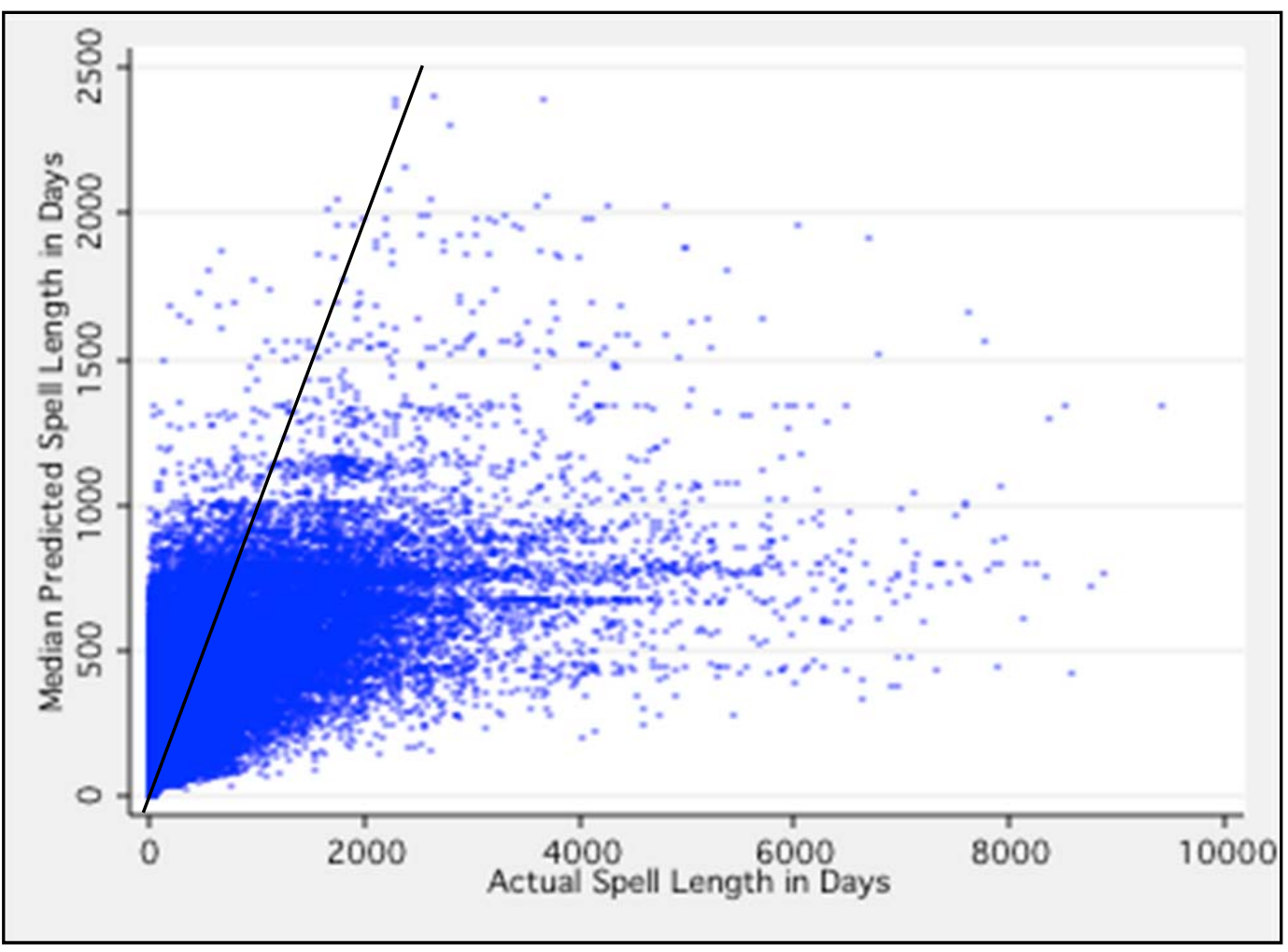


Figure 3: Distribution of Difference Between Actual and Predicted Spell Length

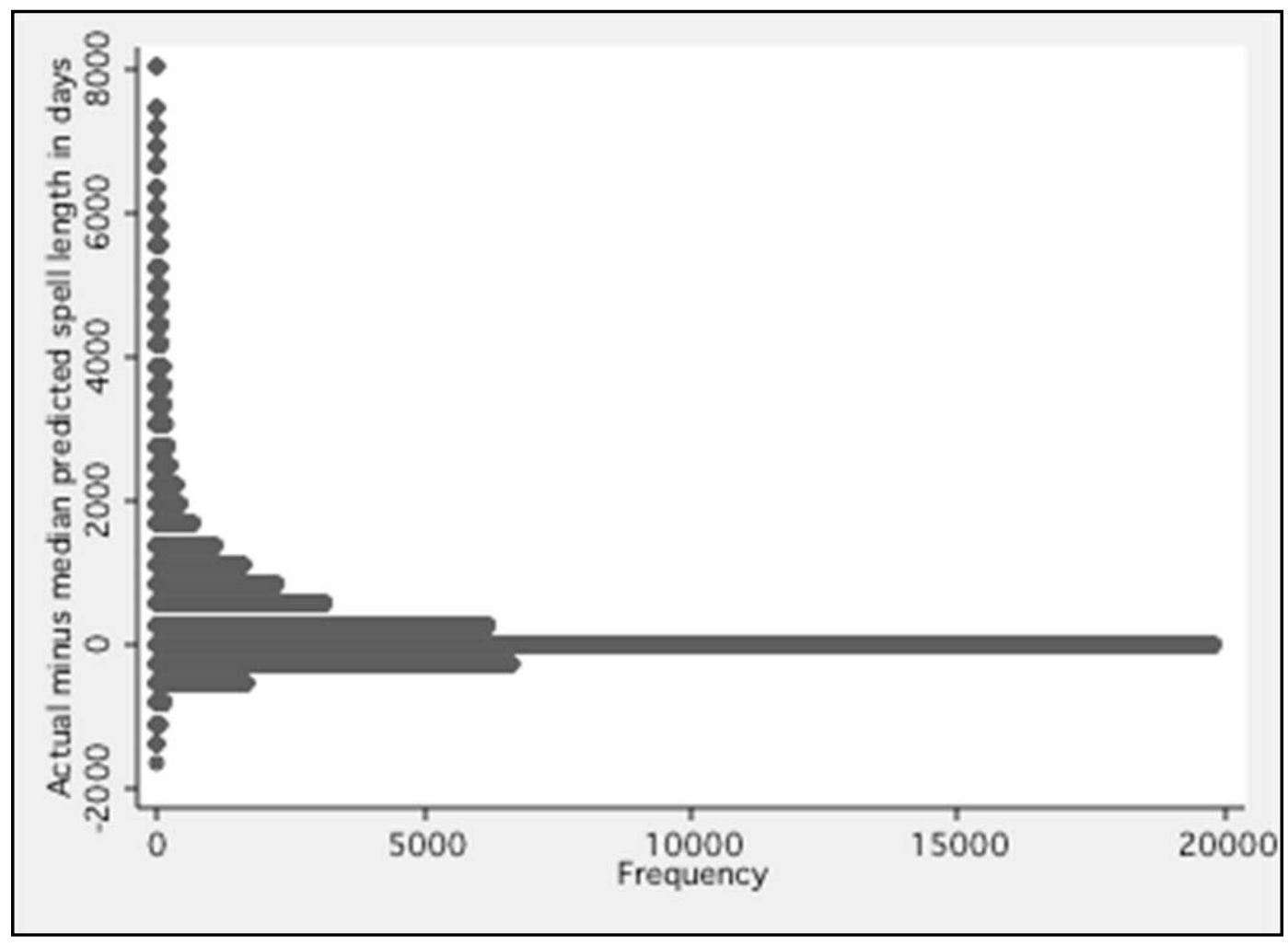

Figure 4: Predicted Annual Inspections from Exponential Model Compared to Actual Annual Inspections

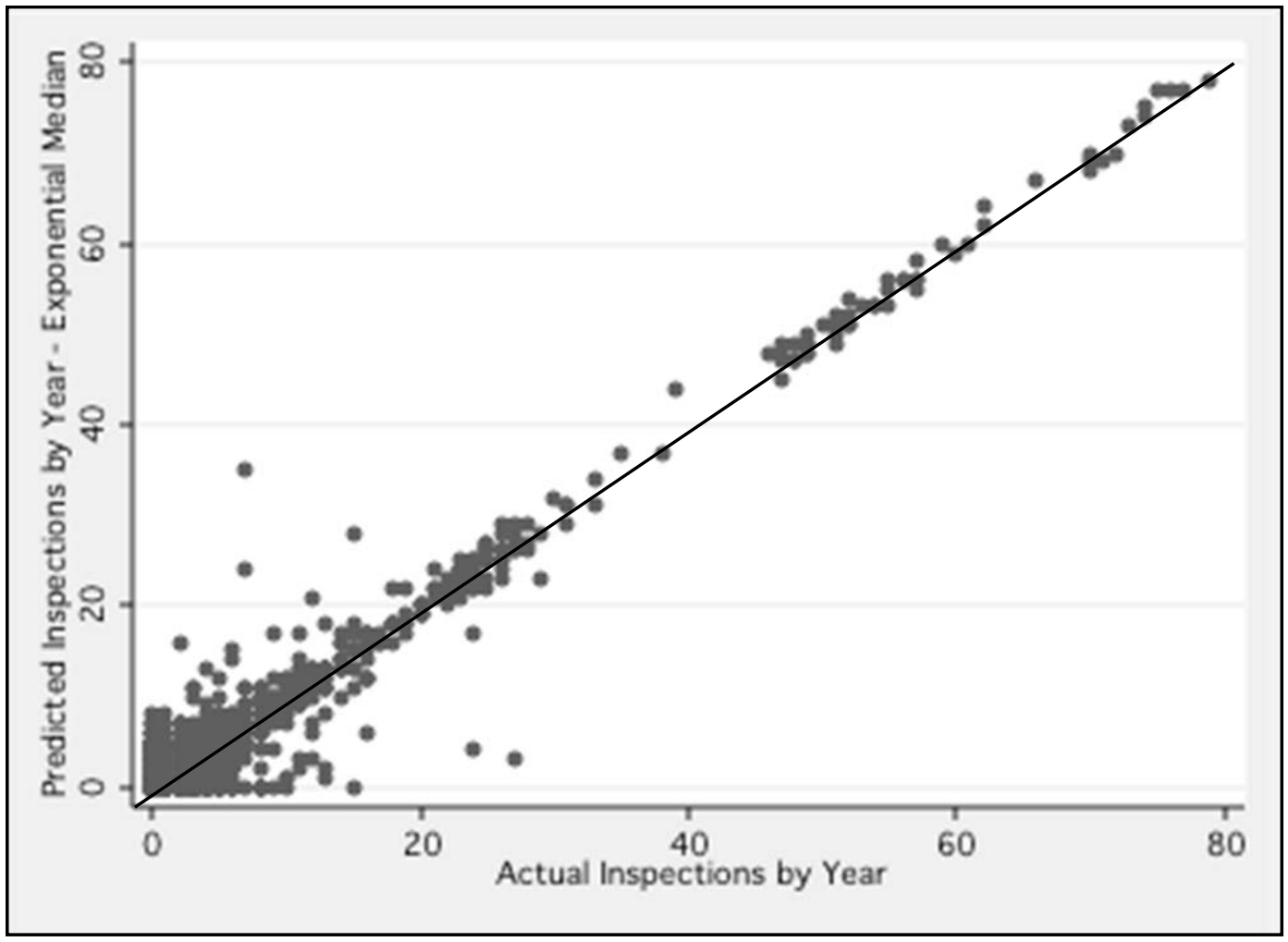


Figure 5: Predicted Annual Inspections from Poisson Model Compared to Actual Annual Inspections

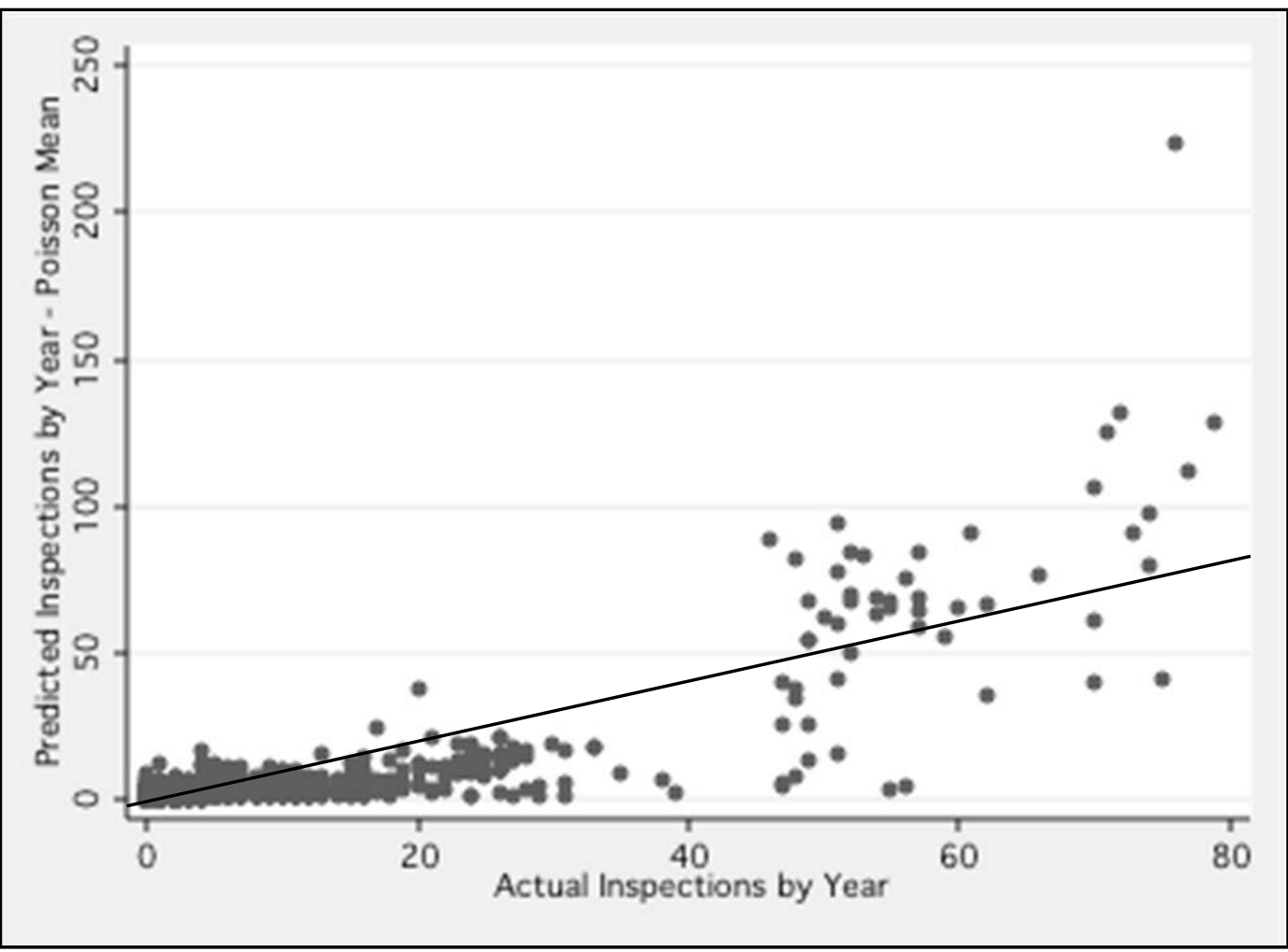

